\title{
Digitizing Non-Invasive Neuromodulation Trials: Scoping Review, Process Mapping, and Recommendations from a Delphi Panel
}

Andre R Brunoni ${ }^{*}$, Hamed Ekhtiari2*, Andrea Antal ${ }^{3}$, Paradee Auvichayapat $\square$, Chris Baeken ${ }^{5,62,63}$, Isabela M. Benseñor ${ }^{6}$, Marom Bikson ${ }^{7}$, Paulo Boggio ${ }^{8}$, Barbara Borroni ${ }^{64}$ Filippo Brighina ${ }^{9}$, Jerome Brunelin ${ }^{10}$, Sandra Carvalho ${ }^{11}$, Wolnei Caumo ${ }^{12}$, Patrick Ciechanski ${ }^{13}$, Leigh Charvet ${ }^{14}$, Vincent P. Clark ${ }^{15}$, Roi Cohen Kadosh $^{27}$, Maria Cotelli ${ }^{65}$, Abhishek Datta ${ }^{16}$, Zhi-De Deng ${ }^{17}$, Rudi De Raedt ${ }^{18}$, Dirk De Ridder ${ }^{19}$, Paul B. Fitzgerald $^{26}$, Agnes Floel ${ }^{20}$, Flavio Frohlich ${ }^{21}$, Mark S. George ${ }^{22}$, Peyman Ghobadi-Azbari ${ }^{66,67}$, Stephan Goerigk $^{23}$, Roy H. Hamilton ${ }^{24}$, Shapour J. Jaberzadeh ${ }^{25}$, Kate Hoy ${ }^{26}$, Dawson J. Kidgell ${ }^{28}$, Arash Khojasteh Zonoozi $^{66,68}$, Adam Kirton ${ }^{69}$, Steven Laureys ${ }^{29}$, Michal Lavidor ${ }^{30}$, Kiwon Lee ${ }^{31}$, Jorge Leite ${ }^{32}$, Sarah H. Lisanby $^{17}$, Colleen Loo ${ }^{33,34}$, Donel M. Martin ${ }^{33,34}$, Carlo Miniussi ${ }^{35}$, Marine Mondino ${ }^{10}$, Katia Monte-Silva ${ }^{36}$, Leon Morales-Quezada ${ }^{37}$, Michael A. Nitsche ${ }^{38}$, Alexandre H. Okano ${ }^{39}$, Claudia S. Oliveira ${ }^{40}$, Balder Onarheim ${ }^{41}$, Kevin Pacheco-Barrios ${ }^{42,43}$, Frank Padberg ${ }^{44}$, Ester M Nakamura-Palacios ${ }^{45}$, Ulrich Palm ${ }^{46}$, Walter Paulus ${ }^{47}$, Christian Plewnia ${ }^{48}$, Alberto Priori ${ }^{70}$, Tarek K. Rajji ${ }^{49}$, Lais B. Razza ${ }^{50,57}$, Erik M. Rehn ${ }^{51}$, Giulio Ruffini ${ }^{52}$, Klaus Schellhorn ${ }^{53}$, Mehran Zare-Bidoky ${ }^{66,71}$, Marcel Simis ${ }^{54}$, Pawel Skorupinski ${ }^{52}$, Paulo Suen $^{50}$, Aurore Thibaut ${ }^{55}$, Leandro C. L. Valiengo ${ }^{56}$, Marie-Anne Vanderhasselt ${ }^{62}$, Sven Vanneste ${ }^{58}$, Ganesan Venkatasubramanian ${ }^{59}$, Ines R. Violante ${ }^{27}$, Anna Wexler ${ }^{60}$, Adam J. Woods ${ }^{61}$, Felipe Fregni ${ }^{42}$

1: Department and Institute of Psychiatry, Faculdade de Medicina da Universidade de São Paulo, R Dr Ovidio Pires de Campos 785, 20 andar, 05403-000, São Paulo, Brazil; Department of Internal Medicine, Faculdade de Medicina da Universidade de São Paulo \& Hospital Universitário, Universidade de São Paulo, Av. Prof Lineu Prestes 2565, 05508-000, São Paulo, Brazil; Laboratory of Neurosciences (LIM-27), Instituto Nacional de Biomarcadores em Neuropsiquiatria (INBioN), Service of Interdisciplinary Neuromodulation (SIN), Department and Institute of Psychiatry, Faculdade de Medicina da Universidade de São Paulo, R Dr Ovidio Pires de Campos 785, 20 andar, 05403-000, São Paulo, Brazil.

2: Laureate Institute for Brain Research (LIBR), 6655 South Yale Ave, Tulsa, OK 74136, USA.

3:Department of Neurology, University Medical Center Göttingen, Göttingen, Germany.

4: Department of Physiology, Faculty of Medicine, Khon Kaen University, Khon Kaen, Thailand.

5: Vrije Universiteit Brussel (VUB): Department of Psychiatry University Hospital (UZBrussel), Brussels, Belgium;

6:Center for Clinical and Epidemiological Research, University of São Paulo, São Paulo, Brazil.

7: The Department of Biomedical Engineering, The City College of New York, The City University of New York, New York, USA.

8: Social and Cognitive Neuroscience Laboratory, Center for Biological Science and Health, Mackenzie Presbyterian University, São Paulo, Brazil.

9: Department of Biomedicine, Neuroscience and Advanced Diagnostics (Bi.N.D.), University of Palermo, Palermo, Italy.

10: Centre Hospitalier le Vinatier, F69500, Bron, France; INSERM U1028, CNRS UMR 5292, PSYR2 Team, Centre de recherche en Neurosciences de Lyon (CRNL), Université Lyon 1, F69000, Lyon, France.

11: Translational Neuropsychology Lab, Department of Education and Psychology and William James Center for Research (WJC

R), University of Aveiro, Campus Universitário de Santiago, Aveiro, Portugal

12:Post-Graduate Program in Medical Sciences, School of Medicine, Universidade Federal do Rio Grande do Sul (UFRGS), Brazil; Laboratory of Pain and Neuromodulation at Hospital de Clínicas de Porto Alegre (HCPA), Porto Alegre, Brazil;

Pain and Palliative Care Service at HCPA, Brazil; Department of Surgery, School of Medicine, UFRGS, Brazil.

13: Faculty of Medicine and Dentistry, University of Alberta, 1-002 Katz Group Centre for Pharmacy and Health Research, Edmonton, Alberta T6G 2E1, Canada.

14: Department of Neurology, NYU Grossman School of Medicine, New York, NY, USA.

15: Psychology Clinical Neuroscience Center, Department of Psychology, The University of New Mexico, Albuquerque, NM, USA.

16: Research and Development, Soterix Medical Inc., New York, USA.

17:Noninvasive Neuromodulation Unit, Experimental Therapeutics \& Pathophysiology Branch, National Institute of Mental Health, Bethesda, MD, USA.

18: Department of Experimental Clinical and Health Psychology, Ghent University, Belgium.

19: Section of Neurosurgery, Department of Surgical Sciences, Dunedin School of Medicine, University of Otago, Dunedin, New Zealand. 
20: Department of Neurology, University Medicine Greifswald, Greifswald, Germany; German Center for Neurodegenerative Diseases (DZNE), Rostock/Greifswald, Germany.

21: Department of Psychiatry, University of North Carolina at Chapel Hill, Chapel Hill, North Carolina; Carolina Center for Neurostimulation, University of North Carolina at Chapel Hill, Chapel Hill, North Carolina; Department of Neurology, University of North Carolina at Chapel Hill, Chapel Hill, North Carolina; Department of Cell Biology and Physiology, University of North Carolina at Chapel Hill, Chapel Hill, North Carolina; Department of Biomedical Engineering, University of North Carolina at Chapel Hill, Chapel Hill, North Carolina; Neuroscience Center, University of North Carolina at Chapel Hill, Chapel Hill, North Carolina.

22:Department of Psychiatry, Medical University of South Carolina, Charleston, SC, 29425, USA; Ralph H. Johnson VA Medical Center, Charleston, SC, 29401, USA.

23: Department of Psychiatry and Psychotherapy, LMU Hospital, Munich, Germany; Department of Psychological Methodology and Assessment, LMU, Munich, Germany; Hochschule Fresenius, University of Applied Sciences, Munich, Germany.

24: Department of Neurology, University of Pennsylvania, Philadelphia, PA, USA.

25: Department of Physiotherapy, Faculty of Medicine, Nursing and Health Sciences, Monash University, Melbourne, Australia.

26: Epworth Centre for Innovation in Mental Health, Epworth Healthcare and Monash University Department of Psychiatry, Camberwell, Victoria, Australia.

27: School Of Psychology, Faculty of Health and Medical Sciences, University Of Surrey, Guildford, UK.

28: Department of Physiotherapy, School of Primary and Allied Health Care, Faculty of Medicine, Nursing and Health Science, Monash University, Melbourne, Australia.

29: Coma Science Group, GIGA-Consciousness, GIGA Institute, University of Liège, Liege, Belgium.

30:Bar Ilan University, Department of Psychology, and the Gonda Brain Research Center, Israel.

31: Ybrain Corporation, Gyeonggi-do, Republic of Korea

32: INPP, Portucalense University, Porto, Portugal.

33: School of Psychiatry, University of New South Wales, Sydney, NSW, Australia.

34: Black Dog Institute, Sydney, NSW, Australia.

35: Center for Mind/Brain Sciences - CIMeC, University of Trento, Rovereto, Italy.

36: Applied Neuroscience Laboratory, Department of Physical Therapy, Universidade Federal de Pernambuco, UFPE, Recife, PE, Brazil; NAPeN Network (Núcleo de Assistência e Pesquisa em Neuromodulação), Brazil.

37: Department of Physical Medicine and Rehabilitation, Spaulding Rehabilitation Hospital, Harvard Medical School, Boston, MA 02215, USA.

38: Department of Psychology and Neurosciences, Leibniz Research Centre for Working Environment and Human Factors, 44139 Dortmund, Germany; Department of Neurology, University Medical Hospital Bergmannsheil, 44789 Bochum, Germany.

39: Center for Mathematics, Computation, and Cognition, Universidade Federal do ABC, São Bernardo do Campo, Brazil; Brazilian Institute of Neuroscience and Neurotechnology (BRAINN/ CEPID-FAPESP), University of Campinas, Campinas, São Paulo, Brazil; NAPeN Network (Núcleo de Assistência e Pesquisa em Neuromodulação), Brazil.

40: Master's and Doctoral Program in Health Sciences, Faculty of Medical Sciences, Santa Casa de São Paulo, São Paulo, Brazil; Master's and Doctoral Program in Human Movement and Rehabilitation, Evangelical University of Goiás, Anápolis, Brazil.

41: PlatoScience ApS, Copenhagen, Denmark.

42: Neuromodulation Center and Center for Clinical Research Learning, Spaulding Rehabilitation

Hospital and Massachusetts General Hospital, Harvard Medical School, Boston, MA 02129, USA.

43: Universidad San Ignacio de Loyola, Vicerrectorado de Investigación, Unidad de Investigación para la Generación y Síntesis de Evidencias en Salud, Lima, Peru.

44: Department of Psychiatry and Psychotherapy, University Hospital, LMU Munich, Nussbaumstrasse 7, 80336 Munich, Germany. 45: Laboratory of Cognitive Sciences and Neuropsychopharmacology, Program of Post-Graduation in Physiological Sciences, Health Sciences Center, Federal University of Espirito Santo, Vitória, ES, Brazil.

46: Department of Psychiatry and Psychotherapy, Klinikum der Universität München, 80336 Munich, Germany; Medical Park Chiemseeblick, Rasthausstr. 25, 83233 Bernau-Felden, Germany.

47: Department of Neurology. Ludwig Maximilians University Munich, Klinikum Großhadern, Marchioninistr. 15, 81377 München

48: Department of Psychiatry and Psychotherapy, Tübingen Center for Mental Health (TüCMH), Neurophysiology and Interventional Neuropsychiatry, University of Tübingen, Calwerstraße 14, 72076, Tübingen, Germany.

49: Centre for Addiction and Mental Health, Toronto, Canada; Temerty Faculty of Medicine, University of Toronto, Toronto, Canada; Toronto Dementia Research Alliance, Toronto, Canada.

50: Service of Interdisciplinary Neuromodulation (SIN), Department and Institute of Psychiatry, Faculdade de Medicina da Universidade de São Paulo, R Dr Ovídio Pires de Campos 785, 20 andar, 05403-000, São Paulo, Brazil.

51: Flow Neuroscience, Malmö, Skane Lan, Sweden.

52: Neuroelectrics Corporation, Cambridge, Massachusetts, USA

53: neuroConn $\mathrm{GmbH}$, 98693, Ilmenau, Germany.

54: Physical and Rehabilitation Medicine Institute, General Hospital, Medical School of the University of Sao Paulo, São Paulo, Brazil. 
medRxiv preprint doi: https://doi.org/10.1101/2022.03.03.22271837; this version posted March 5, 2022. The copyright holder for this preprint (which was not certified by peer review) is the author/funder, who has granted medRxiv a license to display the preprint in perpetuity.

It is made available under a CC-BY-NC-ND 4.0 International license .

55: Coma Science Group, GIGA-Consciousness \& Centre du Cerveau, University and University Hospital of Liège, Liège, Belgium. 56: Laboratory of Neurosciences (LIM-27), Service of Interdisciplinary Neuromodulation (SIN), Department and Institute of Psychiatry, Faculdade de Medicina da Universidade de São Paulo, R Dr Ovídio Pires de Campos 785, 20 andar, 05403-000, São Paulo, Brazil.

57: Department of Head and Skin, Ghent University, Ghent, Belgium; Ghent Experimental Psychiatry (GHEP) Lab, Ghent University, Ghent, Belgium.

58: Lab for Clinical \& Integrative Neuroscience, Trinity College of Neuroscience, Trinity College Dublin, Ireland.

59: Department of Psychiatry, National Institute of Mental Health and Neuro Sciences (NIMHANS), Bengaluru, India.

60: Department of Medical Ethics and Health Policy, University of Pennsylvania, Philadelphia, PA, USA.

61: Center for Cognitive Aging and Memory, McKnight Brain Institute, University of Florida, Gainesville, FL, USA; Department of Clinical and Health Psychology, University of Florida, Gainesville, FL, USA; Department of Neuroscience, University of Florida, Gainesville, FL, USA.

62: Department of Head and Skin, Ghent University Hospital, Ghent University, Ghent, Belgium; Ghent Experimental Psychiatry (GHEP) Lab, Ghent, Belgium.

63: Eindhoven University of Technology, Department of Electrical Engineering, the Netherlands

64:Centre for Neurodegenerative Disorders, Neurology Unit, Department of Clinical and Experimental Sciences, University of Brescia, Italy.

65: Neuropsychology Unit, IRCCS Istituto Centro San Giovanni di Dio Fatebenefratelli, Brescia, Italy.

66: Iranian National Center for Addiction Studies, Tehran University of Medical Sciences, Tehran, Iran.

67:Department of Biomedical Engineering, Shahed University, Tehran, Iran.

68: Student Research Committee, Faculty of Medicine, Mashhad University of Medical Sciences, Mashhad, Iran.

69: Department of Clinical Neurosciences and Department of Pediatrics, University of Calgary, Calgary, Alberta, Canada.

70: Aldo Ravelli Research Center for Neurotechnology and Experimental Neurotherapeutics, Department of Health Sciences, University of Milan, Milan, Italy.

71: School of Medicine, Shahid-Sadoughi University of Medical Sciences, Yazd, Iran.

Corresponding author: André Russowsky Brunoni, MD, PhD, Service of Interdisciplinary Neuromodulation, $\mathrm{R}$ Dr

Ovídio Pires de Campos 785, 20 andar Ala Sul, Instituto de Psiquiatria, CEP 05403-000, São Paulo, Brazil, brunoni@usp.br

Word count: 3717 words in the main text and 149 words in the abstract.

63 references.

The manuscript contains 1 graphical abstract, 6 figures, 1 table and is accompanied by a Supplementary Material. 
medRxiv preprint doi: https://doi.org/10.1101/2022.03.03.22271837; this version posted March 5, 2022. The copyright holder for this preprint (which was not certified by peer review) is the author/funder, who has granted medRxiv a license to display the preprint in perpetuity.

It is made available under a CC-BY-NC-ND 4.0 International license .

\section{Abstract}

Although relatively costly and non-scalable, non-invasive neuromodulation interventions are treatment alternatives for neuropsychiatric disorders. The recent developments of highly-deployable transcranial electric stimulation (tES) systems, combined with mobile-Health technologies, could be incorporated in digital trials to overcome methodological barriers and increase equity of access. We convened 61 highlyproductive specialists and contacted 8 tES companies to assess 71 issues related to tES digitalization readiness, and processes, barriers, advantages, and opportunities for implementing tES digital trials. Delphi-based recommendations (>60\% agreement) were provided. Device appraisal showed moderate digitalization readiness, with high safety and possibility of trial implementation, but low connectivity. Panelists recognized the potential of tES for scalability, generalizability, and leverage of digital trials processes; although they reached no consensus about aspects regarding methodological biases. We further propose and discuss a conceptual framework for exploiting shared aspects between mobile-Health tES technologies with digital trials methodology to drive future efforts for digitizing tES trials.

\section{Keywords}

Mobile Health, non-invasive neuromodulation, digital health, systematic review, Delphi panel. 
medRxiv preprint doi: https://doi.org/10.1101/2022.03.03.22271837; this version posted March 5, 2022. The copyright holder for this preprint

(which was not certified by peer review) is the author/funder, who has granted medRxiv a license to display the preprint in perpetuity.

It is made available under a CC-BY-NC-ND 4.0 International license .

\section{Graphical Abstract. Consensus Roadmap.}

\section{tES Digital Trial Consensus Roadmap}

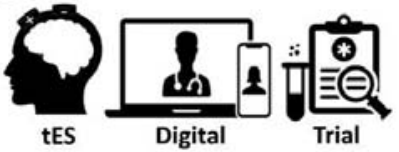

\section{A} Recruitment Process

Mapping Research Problem

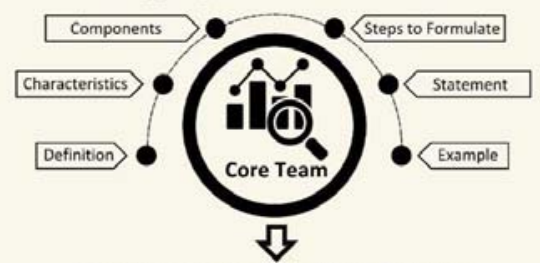

Identifying and Inviting Experts

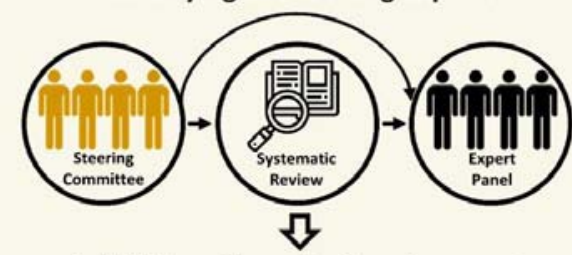

Initial Questionnaire Development

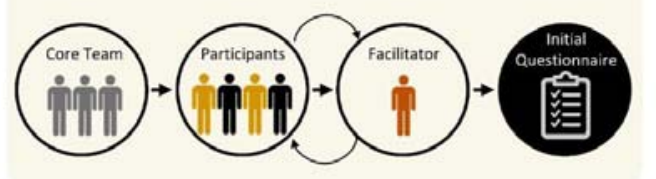

B Evidence Synthesis

Company Assessment

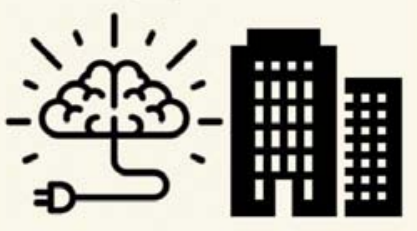

Process Mapping

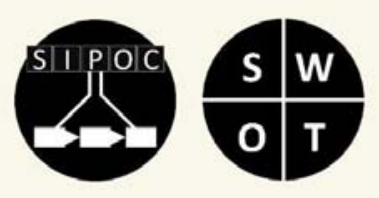

Clinical Trial Methodology

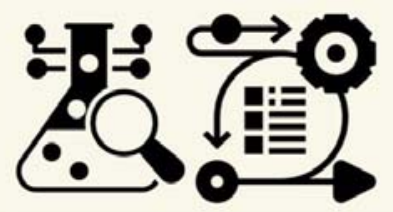

\section{C}

\section{Consensus Development}

Questionnaire

Development and Validation

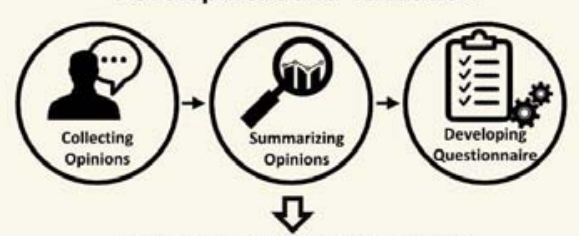

Data Collection and Analysis

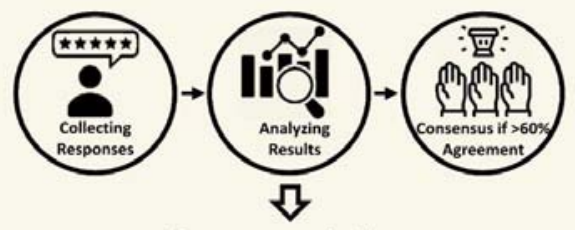

Recommendations

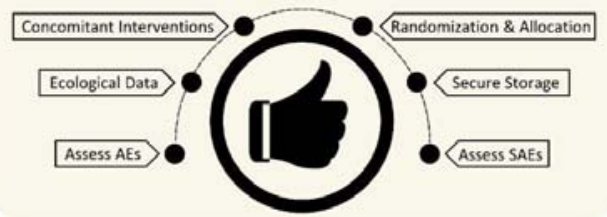

(A) Recruitment process. The study procedure started with defining the components of the research problem by the core research team. After defining the problems, two different sets of participants (the steering committee (SC) including key leaders of the field identified by the core team and the expert panel (EP) as a more diverse group of experts identified based on the number of publications based on a systematic review) were identified and were invited to participate in a Delphi study. The study facilitators (first and last authors) led the communications with the SC to design the initial questionnaire through an iterative approach. (B) Evidence synthesis: To collect the available evidence, companies producing portable tES (ptES) devices were contacted, based on the companies suggested by the SC and EP to provide details about the available devices. For mapping methodological processes of digitizing tES trials, two distinct strategies were performed and embedded into the questionnaire, namely SIPOC (Suppliers, Inputs, Process, Outputs and Customer) and SWOT (Strengths, Weaknesses, Opportunities, and Threats) assessment were performed and embedded into the questionnaire. (C) Consensus development: In the next phase, the questionnaire was validated and finalized via collecting and summarizing opinions. Afterwards, the SC and EP responded to the final questionnaire and results were analyzed providing a list of recommendations for running tES digital trials based on a pre-registered consensus threshold. 
medRxiv preprint doi: https://doi.org/10.1101/2022.03.03.22271837; this version posted March 5, 2022. The copyright holder for this preprint (which was not certified by peer review) is the author/funder, who has granted medRxiv a license to display the preprint in perpetuity.

It is made available under a CC-BY-NC-ND 4.0 International license .

\section{Introduction}

Transcranial electric stimulation (tES) is a non-invasive neuromodulation intervention that uses electric currents applied over the scalp to modify cortical activity and treat neuropsychiatric disorders, and has high safety and tolerability ${ }^{1}$. Notwithstanding, due to its low-to-moderate efficacy for several conditions, the consensus of its readiness for clinical use across indications varies ${ }^{2,3}$, and regulatory approvals across regions are mixed ${ }^{4,5}$, warranting larger-scale clinical trials ${ }^{6}$. However, these trials are hampered by the need for daily visits to the research center to deliver the necessary number of tES sessions, which limits recruitment, harms adherence, increases $\operatorname{costs}^{6}$, and restricts diversity ${ }^{7,8}$.

Unlike other non-invasive neuromodulation modalities, tES devices, by virtue of being affordable and battery-powered ${ }^{9}$, are portable, making the intervention an appealing brain stimulation modality for patients who do not tolerate pharmacotherapy ${ }^{10}$ or have difficulty attending for treatment at a clinical centre, In fact, several companies have been designing highly-deployable tES devices that could be used to address issues of scale, access, and patients' burden in the context of digital trials - i.e., trials that leverage aspects such as recruitment, assessment, and data analyses through the implementation of digital technologies ${ }^{11}$. These approaches could be further integrated with mobile Health devices, apps and wearables, allowing for several new implementations, such as simultaneous combination with cognitive and psychological interventions, ecological momentary assessment of behaviors, passive data collection, and digital phenotyping ${ }^{12,13}$.

However, since protocols and standards for digital trials using mobile tES are still emerging, the challenges and opportunities of their implementation processes have not yet been systematically examined. Moreover, issues on rigor and reproducibility - for instance, best practices to perform randomization, allocation concealment, and sham stimulation - and generalizability - how to fully explore their potential for scalability while ensuring adherence and representativeness - have only been discussed in non-digital contexts ${ }^{7,8,14}$. Finally, implementation challenges are different in low-/middle- income countries, which present lower digital literacy, fluence in non-native languages, and wireless connectivity ${ }^{15}$; conversely, scalable mobile Health interventions have even higher impact potential in such countries ${ }^{16}$.

Considering these challenges, we systematically identified non-invasive neuromodulation specialists to elaborate and discuss issues related to the extent, processes, and methodological characteristics of digitizing non-invasive neuromodulation trials. These findings, supplemented by a systematic scoping review of tES clinical research articles and an assessment of the digitalization degree of commercially available tES devices, provided a key summary of Delphi-based recommendations for enhancing the implementation of digital tES trials. 
medRxiv preprint doi: https://doi.org/10.1101/2022.03.03.22271837; this version posted March 5, 2022. The copyright holder for this preprint (which was not certified by peer review) is the author/funder, who has granted medRxiv a license to display the preprint in perpetuity.

It is made available under a CC-BY-NC-ND 4.0 International license .

\section{Methods}

Our protocol was pre-registered at the Open Science Framework (OSF) ${ }^{17}$ and is depicted in figure 1. Minor deviations occurred (Sup. Material - Appendix 1).

(Figure-1)

Specialist panel

We used a Delphi technique, in which comments and feedback are iteratively discussed ${ }^{18}$, for addressing challenges and proposing recommendations for digitizing tES trials. Following recent papers ${ }^{19,20}$, we initially convened a steering committee (SC) group, formed based on the collaborative network of the leading authors, to develop structured questionnaires with items using Five-point Likert scales or open questions (Supplementary Material - Appendix 2). The SC also provided qualitative feedback on several topics that was analyzed by the leading authors and qualitatively described here. Afterwards, the SC interacted with a larger expert panel (EP) to rate each item. The EP members were selected among the most productive authors in the field, identified through a systematic review of recent tES clinical trials in a 10-year span (Sup. Material - Appendix 3). Several interactions were performed between the EP and SC until a final manuscript version was assembled. Consensus was achieved by a $>60 \%$ agreement of all panelists. Electronic questionnaires were used in all steps of this process. All members of the SC and the EP consented to have their names listed and identified in the manuscript.

\section{Systematic scoping review}

A systematic scoping review ${ }^{21}$ was performed to identify tES reviews, consensus papers, and guidelines to select characteristics for composing the questionnaires used in the rating phase (Sup. Material - Appendix 4).

\section{tES digitalization readiness}

Companies producing tES devices were identified through specialist referrals and web search and surveyed using structured questionnaires to assess their digitalization readiness, according to connectivity, readiness for digital trials, parameter space flexibility, ecological footprint, front-end interface, and data security (Sup. Material - Appendix 5). 
medRxiv preprint doi: https://doi.org/10.1101/2022.03.03.22271837; this version posted March 5, 2022. The copyright holder for this preprint (which was not certified by peer review) is the author/funder, who has granted medRxiv a license to display the preprint in perpetuity.

It is made available under a CC-BY-NC-ND 4.0 International license .

We used SWOT (Strengths, Weaknesses, Opportunities and Threats) and SIPOC (Suppliers, Inputs, Process, Outputs, Customers) approaches to respectively identify external and internal negative and positive aspects for digitizing tES trials and map and compare processes related to standard and digital tES trials. The methodological assessment was based on perceived challenges and advantages, identified through questionnaires, of conducting such trials (Sup. Material - Appendix 2).

Role of the funding source

This work received no specific funding from any source.

\section{Results}

\section{Specialist panel}

For the SC, 34 authors were invited and all agreed to participate. For the EP, out of 43 authors who were identified, 14 did not reply to our contacts, and 2 declined to participate. Finally, 27 participants constituted the EP (Sup. Material - Appendix 6). Most panelists were men (70\%), experienced (78\% with > 10 years of experience in the field) and between 40 to 49 years-old (44\% and 33\% of the SC and the EP). They resided in the US (SC $n=11$, EP $n=3$ ), Brazil ( $S C n=6$, EP $n=5)$, Germany ( $S C n=5$, EP $n=4)$, and 13 other countries (Sup. Material - Appendix 7). Only 15\% and 18\% of the SC and EP members, respectively, were not conducting at least one tES trial with digital features; most were actually principal investigators (83\%) of such trials.

\section{Systematic scoping review}

Our initial search yielded 443 references, and 34 articles met the inclusion criteria of our scoping review, including 9 recommendation articles ${ }^{4,7,22-28}, 10$ guidelines ${ }^{3,8,14,29-35}, 10$ critical reviews ${ }^{36-45}$, and 5 expert consensus articles ${ }^{6,7,35,46,472,48-51}$, which were used for elaborating the study questionnaires (Sup. Material Appendix 8).

\section{tES digitalization readiness}

Eight of 13 companies contacted provided feedback. Digitization readiness varied according to their wireless connectivity, readiness for digital trials, flexibility of parameter space, ecological footprint, front-end interface, and data security. Markedly, current systems have limited wireless connectivity, which is a barrier for device-to-device communication with wearables and third-party apps that could enhance portability potential (eg, apps collecting biological data, and mobile mental Health apps). Conversely, most systems 
medRxiv preprint doi: https://doi.org/10.1101/2022.03.03.22271837; this version posted March 5, 2022. The copyright holder for this preprint (which was not certified by peer review) is the author/funder, who has granted medRxiv a license to display the preprint in perpetuity.

It is made available under a CC-BY-NC-ND 4.0 International license .

currently present good data security protocols (reported HIPAA or GDPR compliance), flexibility of tES parameter space, and readiness for digital trials (figure 2).

(Figure-2)

\section{SWOT assessment}

The identified characteristics and quantitative agreement rating composing the SWOT assessment is displayed in figure 3. Qualitative aspects are briefly discussed here and detailed in the Sup. Material Appendix 9.

(Figure-3)

Regarding strengths, the panelists agreed on four features: a) high safety, considering previous evidence from non-digital trials and studies in humans ${ }^{35,47,52,53}$; b) feasibility of self-application, owing to recent developments of devices in which electrode placement is fixed, methods for easy strap positioning, and friendly end-user interface of mobile tES devices ${ }^{8}$; c) being a non-pharmacological intervention; and d) affordability, as tES devices are simple to be built in terms of electric engineering ${ }^{9}$, costs of high-end features (e.g. microprocessors, bluetooth and wireless connectivity, miniaturization) are decreasing over time, and self-application saves human resources.

Regarding weaknesses, panelists agreed on two aspects: a) difficulties in remote supervision, raising concerns regarding patients themselves manipulating tES devices, which could lead to misuse, diversion of the device, or its use outside of medical contexts, further impacting on reproducibility of findings; b) and difficulties in obtaining accurate placement of electrodes, as deviations in electrode positioning and orientation might affect outcomes ${ }^{9}$. Therefore, companies should develop and test new methods for assuring correct placement of electrodes ${ }^{26}$. Other potential weaknesses did not reach consensus, such as concerns related to bioethics, particularly regarding equity to access; increased (compared to on-site tES trials) risks of common and serious adverse events ${ }^{31}$; and relatively low evidence of clinical efficacy for most conditions ${ }^{3}$.

Regarding opportunities, six aspects reached agreement: a) scalability, as, compared to on-site tES trials that need physical space, staff to apply sessions and commute of participants, digital trials using mobile tES devices do not have such constraints, allowing research assistants to monitor several participants at once, at any distance from the study centers; b) telemedicine, which has been widely adopted during the COVID19 pandemic, facilitating its adoption in digital trials; c) employment of combined mobile Health technologies, permitting digital phenotyping ${ }^{13}$ and combination with digital interventions when using paired wearables and smartphone applications; d) automatization of procedures (see SIPOC below); e) $5 \mathrm{G} /$ 
medRxiv preprint doi: https://doi.org/10.1101/2022.03.03.22271837; this version posted March 5, 2022. The copyright holder for this preprint (which was not certified by peer review) is the author/funder, who has granted medRxiv a license to display the preprint in perpetuity.

It is made available under a CC-BY-NC-ND 4.0 International license .

Internet of Things, which can boost connectivity and data processing, leveraging data collection ${ }^{13}$ and eventually allowing the development of mobile closed-loop tES systems ${ }^{38}$; and f) use of design thinking approaches, i.e., customizing mobile tES devices around the patients' perspectives ${ }^{54}$, for instance, to accommodate those with physical or cognitive impairments.

Finally, two threats reached consensus: a) recreation and do-it-yourself misuse, which could lead to unexpected adverse events and safety issues ${ }^{24}$; and b) regulatory status, as medical devices require formal regulatory approval in the US ${ }^{55}$ and Europe ${ }^{56}$, although some tES devices are marketed as wellness devices, have regulatory device exemptions ${ }^{5}$, or can be approved by similarity ${ }^{5}$. Further, mobile tES devices could have additional regulations, if framed as mobile Health systems ${ }^{57}$. Additionally, two potential threats were identified by most of the panel, but did not reach the $60 \%$ consensus threshold: a) risks related to hacking and cyber-security, as observed in mobile Health devices ${ }^{58}$, and b) risks related to confidentiality and anonymity.

SIPOC

We identified 4 main processes (recruitment, pre-screening, screening, and participation) in which digitization and automatization procedures can leverage mobile tES trials (Table 1). The panelists noted that trials might not be purely digital or analog, and different degrees of digital features can occur at each process. For instance, participants can be recruited through social media, but screened onsite. Moreover, digital processes can provide enhanced metrics to adjust processes, recruit faster, and follow participants for longer periods. Finally, digitization processes provide scalability due to the use of digital assessments and telemedicine. (Table 1).

(Table-1)

Methodological aspects

The panelists examined 24 methodological aspects of digital trials using mobile tES devices, reaching consensus in 12 of them (figure 4). They are briefly discussed here and detailed in the Sup. Material Appendix 10.

(Figure-4)

Of the 12 aspects that reached consensus, 10 were perceived as advantages of digital trials, which included a) the adoption of different study designs, including b) adaptive designs, as adaptation rules can be 
medRxiv preprint doi: https://doi.org/10.1101/2022.03.03.22271837; this version posted March 5, 2022. The copyright holder for this preprint (which was not certified by peer review) is the author/funder, who has granted medRxiv a license to display the preprint in perpetuity.

It is made available under a CC-BY-NC-ND 4.0 International license .

performed automatically and remotely whether data are collected and analyzed by mobile tES systems. Panelists also considered that c) tES devices are already sufficiently developed to be used remotely, which allows for d) longer follow-up periods and e) higher recruitment rates, being f) faster and more efficient than on-site trials. Also, g) greater external validity compared to on-site trials were perceived. Finally, other advantages were the potential for $h$ ) collecting more data than on-site trials, i) combination with other therapies, and j) scalability. The 2 disadvantages / challenges that reached consensus were: a) the necessity of validating new tES parameters, methodologies, and indications first in on-site studies, and $b$ ) the need of developing better remote assessment methods, such as behavioral clinical scales properly designed and validated to be employed remotely.

The items that did not reach consensus mostly pertain to internal validity issues. Interestingly, a significant portion of panelists were undecided on these issues (figure 5). Of note, interesting remarks (detailed in Sup. Material - Appendix 10) were made for: a) randomization-allocation procedures that are done using either specific devices or apps/softwares, but can be vulnerable to contamination biases due to hacking and exposure of the randomization list; b) study blinding, as blinding breaking can occur if devices are manipulated; c) sham stimulation, which can also be revealed due to device manipulation.

\section{Recommendations}

The panelists recommended that teams performing tES digital trials should have members specialized in: a) digital marketing strategies, to enhance online recruitment; b) data science and visualization, for data collection and analysis; c) front-end interfaces, to enhance user experience; d) back-end programming; e) issues related to data security, integrity, anonymity, and replicability ${ }^{25,26}$. Also, they suggested that f) a team member should be always (“24/7”) available (figure 5).

(Figure-5)

Regarding further research, most panelists recommended that better methods for (a) randomization / allocation, and (b) sham should be explored. Also, further research was recommended to develop or refine methods to enhance (c) adherence and (d) external validity of the trials. Also, more research should be devoted to aspects such as (e) combination of interventions, (f) biobehavioral data collection, $(g)$ enhanced data security, and methods to assess (h) serious and (i) unexpected adverse events (details in Sup. Material - Appendix 11). 
medRxiv preprint doi: https://doi.org/10.1101/2022.03.03.22271837; this version posted March 5, 2022. The copyright holder for this preprint (which was not certified by peer review) is the author/funder, who has granted medRxiv a license to display the preprint in perpetuity. It is made available under a CC-BY-NC-ND 4.0 International license .

\section{Discussion}

By convening a diverse group of 61 worldwide specialists in the field of non-invasive neuromodulation, we performed the first systematic assessment and Delphi-based validation of perceived challenges, opportunities, methodological issues, and recommendations on digitizing non-invasive neuromodulation trials. We used several strategies to organize and describe these assessments, such as processing mapping strategies, a systematic scoping review of the literature, iterative rating and validation of structured questionnaires by specialists, and assessment of the digital readiness of commercial tES devices. Taken together, our findings show that performing digital trials using mobile tES devices has complementary advantages and can overcome major on-site tES trial challenges, namely the intensive treatment schedules ${ }^{23}$, transportation costs, accessibility, and scalability ${ }^{8}$. By performing trials remotely, dislocation burdens are decreased, as well as the need for space at the research center, and of trained staff for delivering tES sessions, aspects that increase trial duration ${ }^{6,59}$. Additionally, tES devices are highly scalable, as a single team member can monitor several people at once, provided that tES devices are easy to manipulate, handle, and can be self-delivered. Such scalability gains could be leveraged in faster trials with larger sample sizes, longer follow-up periods, and employing digital recruitment strategies. Considering our results, we propose and further discuss a conceptual framework for digitizing neuromodulation, combining concepts of digital clinical trials with mobile tES (figure 6).

(Figure-6)

\section{Mobile tES devices}

To the best of our knowledge, the term "mobile tES" has not been used yet to describe the combination of highly-deployable neuromodulation devices paired with other wearables or apps. This terminology frames tES in the context of mobile Health devices ${ }^{57}$, encouraging the exploitation of contact points between these two growing fields. However, even though several issues for deployable and remote use have already been addressed (eg, decreasing prices, rechargeable batteries, tailored sponges, sham stimulation, easiness of electrode positioning and of programming session stimulation parameters), our findings showed that no commercial tES devices have been fully digitized yet, presenting different degrees of online, wired, or wireless connectivity. Also, especially for offline devices, methods for restricting the number of sessions allowed per day were not identified. Additionally, most systems neither collect active or passive data, nor present friendly-user interfaces.

The panelists agreed on several opportunities; however, most are distant from immediate implementation. For instance, device-to-device communication ("Internet of Things") would need pairing with third-party apps 
medRxiv preprint doi: https://doi.org/10.1101/2022.03.03.22271837; this version posted March 5, 2022. The copyright holder for this preprint (which was not certified by peer review) is the author/funder, who has granted medRxiv a license to display the preprint in perpetuity. It is made available under a CC-BY-NC-ND 4.0 International license .

or wearables, which is not yet available. This limits other perceived opportunities such as digital phenotyping, combination with psychological or cognitive app interventions, and seamless automatization with other platforms and digital processes.

\section{Methodological challenges, advantages, and processes of digital trials}

The impact of digitizing neuromodulation trials on external validity seems mostly positive, considering that subjects who would not be enrolled in on-site trials are reached. In fact, on-site trial samples are likely to be composed by those with free time and/or living near the clinical center to receive the sessions. Notwithstanding, it is still possible that those younger, richer, more educated, with higher digital literacy, and living in urban areas are preferentially enrolled in digital trials. Also, if recruitment strategies are performed solely using social media, the trial results would have restricted generalizability for people that do not use such media. This could be overcome by using segmented digital marketing campaigns. Likewise, attrition rates might not necessarily be lower in digital trials - although not needing to return daily to the clinical center could decrease burden and minimize dropouts, samples from digital trials might face less engagement and more difficulties in self-delivering the sessions. The lack of daily contact with the clinical staff could also decrease motivation and increase dropouts. In addition, direct social contact, social support and social connectedness outside the digital environment can influence attrition rates of clinical trials. Therefore, tele-monitoring and proper interaction with participants, managing their expectations and credibility of the team, and reinforcing the need to abide by the study protocol, could avoid dropouts.

Panelists also emphasized that methodological issues that have not been completely addressed in on-site trials can be magnified in digital trials ${ }^{14,26}$. For instance, if the process of randomization - allocation concealment - is hacked from the server and publicly exposed, the entire trial can be lost (or, at least, suspended until a new list is generated). Moreover, blinding and sham stimulation issues are not completely resolved issues in on-site trials ${ }^{60}$, and biases arising from these steps are more likely to occur (eg, sham stimulation can be unconcealed by measuring the voltage between electrodes ${ }^{9}$ ) and harm the entire study (for example, by exposing methodological vulnerabilities on the Web). Additionally, issues that would be minor in on-site trials might be more relevant in online trials. For instance, stimulation sessions can be performed in on-site trials appropriately and guarantee adherence ${ }^{9}$, but, in digital trials, some degree of remote monitoring would be necessary for ensuring these aspects.

Finally, there are unique new challenges for digitizing neuromodulation. Even though cyber-hacking is not usually discussed in the environment of clinical trials, government and big company systems are being increasingly hacked. Data anonymity and confidentiality are additional aspects of vulnerability more relevant than in on-site trials, if, for instance, information is also recorded in the devices, smartphones, or is 
medRxiv preprint doi: https://doi.org/10.1101/2022.03.03.22271837; this version posted March 5, 2022. The copyright holder for this preprint (which was not certified by peer review) is the author/funder, who has granted medRxiv a license to display the preprint in perpetuity. It is made available under a CC-BY-NC-ND 4.0 International license .

transmitted remotely. Data collection using standard behavioral scales (for instance, scales for depression) and adverse events need to be further validated to be used online and remotely to avoid instrumental biases. Finally, even open pre-publication of study protocols, which enhances transparency and reproducibility, cannot be fully detailed in digital trials, as a complete description of the groups, blinding methods, and sham stimulation of the protocols could be harmful to the internal validity of digital trials ${ }^{8,14}$.

\section{Limitations}

Although we systematically reviewed the literature for selecting the most productive authors in neuromodulation, experts publishing in non-English databases might not have been selected. In addition, most of the panelists are from high-income countries, limiting the experience, feedback, and number of votes of panelists from low-/middle- income countries, where $85 \%$ of the world population lives, and with probably additional issues on digitalization, including availability. Moreover, our search might not have identified emerging young experts as we have established a threshold based on the number of publications. Although we considered different methods for composing the EP, such as "snowball sampling" based on recommendations from the SC members, and search of other databases such as clinicaltrials.gov, preprints and conference publications, these processes would be non-systematic or involve gray areas in the literature. We also did not assess other stakeholders besides people from industry and academia that could have been relevant for our work, such as patients, governmental and nongovernmental organizations. Moreover, only 8 of 13 companies replied to our contacts, despite several emails that were sent to reach them, and even offering the possibility of online meetings to discuss this work. Although we could have extracted company information based on public information, we opted for not doing that as some information could have been inaccurate. Finally, no large tES digital trials have been finished and published yet; therefore, the processes and challenges described here are mostly theoretical and should be iteratively updated as the field develops. Interestingly, the lack of consensus on issues related to its disadvantages, risks, and biases, with many specialists remaining undecided, indicates that the field is still in its infancy.

\section{Future directions}

The recommendations for teams conducting digital neuromodulation trials markedly diverge from on-site trials that are centered on clinical specialists and staff trained in performing biomedical procedures. The feasibility of these recommendations should be further debated, as they would require more resources. In fact, most recommendations fit with companies and for pivotal studies, and not necessarily for teams running pilot studies that would not have all the capabilities recommended above. For instance, third-party services could be contracted to do specific tasks related to software and hardware development, or such aspects could be developed together by researchers and companies. Moreover, recommendations such as 
medRxiv preprint doi: https://doi.org/10.1101/2022.03.03.22271837; this version posted March 5, 2022. The copyright holder for this preprint (which was not certified by peer review) is the author/funder, who has granted medRxiv a license to display the preprint in perpetuity. It is made available under a CC-BY-NC-ND 4.0 International license .

a support team being always available for medical urgencies, although optimal, might be unrealistic even with large resources. Such issues would need to be carefully discussed with internal review boards and ethics committees to guarantee patient safety without harming trial feasibility.

The recommendations for further research in some aspects specifically related to internal validity, and also external validity, were largely convergent, reaching $70-80 \%$ agreement rates. Taken together, these recommendations call for new standards and best practices of fundamental pillars of tES clinical research, such as methods for sham stimulation, randomization, allocation and assessment of adverse events. In fact, these methodologies have been steadily built over the last decade ${ }^{6,7,10}$ and, although challenged in certain aspects such as sham and blinding ${ }^{60,61}$, they have been largely used in clinical trials ${ }^{26}$. Although several approaches could be used, in a first step relatively simple randomized studies involving healthy participants could use parameters such as blinding efficacy and rate of adverse events as outcome measures, comparing whether they are different in those receiving on-site vs. online tES. Pilot studies using mobile tES in clinical samples are also encouraged to report their methodological approaches and challenges ${ }^{62,63}$.

\section{Conclusion}

In this first Delphi Panel evaluating opportunities, risks, and methodological issues regarding digitizing tES trials, we provided a landscape of this new approach and reached consensus on several recommendations that should be evaluated in further studies. The panel of specialists agreed on advantages associated with the implementation of tES trials; however, considering the fast-growing digitalization in Medicine and Biotechnology, there is a pressing need to better understand how to adapt tES trials to be performed remotely, with a clearer knowledge regarding its positive and negative aspects.

\section{Declaration of interests}

AD, RCK, ER, F. Frohlich, KH, KS, MB, PF: have equity in a company. F. Frohlich, FP, MG, MB, MN, PF, RCK, S. Laureys, WP: are members of the Scientific Advisory Board of a company. AA, F. Frohlich, FP, KMS, MB, MN, RCK, S. Laureys, UP: received honoraria of a company. CB, CL, DD, FP, KMS, S. Laureys, TR, WP: received in-kind support of a company; MC, received financial support by the Italian Ministry of Health (Ricerca Corrente); AD, RCK, ER, F. Frohlich, KS, CP: has a chief role in a company. EMNP: Scientific consulting for a company. AD, KS, MB, PF, RCK, WP: have patents related to a company. ARB receives scholarships and support from FAPESP, the Brazilian National Council of Scientific Development (CNPq-1B), University of São Paulo Medical School (FMUSP), the UK Academy of Medical Sciences (Newton Advanced Fellowship), and the International Health Cohort Consortium (IHCC). HE is supported by the Laureate Institute for Brain Research (LIBR), Warren K. Family Foundation, Oklahoma Center for Advancement of Science and Technologies (OCAST, \#HR18-139) and Brain and Behavior Foundation (NARSAD Young Investigator Award \#27305). AA is supported by the VW Foundation German 2018 - 
medRxiv preprint doi: https://doi.org/10.1101/2022.03.03.22271837; this version posted March 5, 2022. The copyright holder for this preprint (which was not certified by peer review) is the author/funder, who has granted medRxiv a license to display the preprint in perpetuity. It is made available under a CC-BY-NC-ND 4.0 International license .

Israeli Cooperation in Biological and Life Sciences, Medicine (A128416) and by the BMBF (Stimcode, 01FP2124B). TKR has received research support from Brain Canada, Brain and Behavior Research Foundation, BrightFocus Foundation, Canada Foundation for Innovation, Canada Research Chair, Canadian Institutes of Health Research, Centre for Aging and Brain Health Innovation, National Institutes of Health, Ontario Ministry of Health and Long-Term Care, Ontario Ministry of Research and Innovation, and the Weston Brain Institute. TKR also received for an investigator-initiated study in-kind equipment support from Newronika, and in-kind research online accounts from Scientific Brain Training Pro, and participated in 2021 in an advisory board for Biogen Canada Inc. TKR is also an inventor on the United States Provisional Patent No. 17/396,030 that describes cell-based assays and kits for assessing serum cholinergic receptor activity. JL receives scholarship and support from the Portuguese Foundation for Science and Technology (FCT), co-funded through COMPETE 2020 - PO Competitividade e Internacionalização/Portugal 2020/European Union, FEDER (Fundos Europeus Estruturais e de Investimento - FEEI) under the number: PTDC/PSI-ESP/30280/2017. SC receives scholarship and support from the Portuguese Foundation for Science and Technology (FCT), co-funded through COMPETE 2020 - PO Competitividade e Internacionalização/Portugal 2020/European Union, FEDER (Fundos Europeus Estruturais e de Investimento - FEEI) under the number:PTDC/PSI-ESP/29701/2017. CL has received research funding from the Australian National Health and Medical Research Council and Stanley Medical Research Foundation. GV (Ganesan Venkatasubramanian) is supported by the Department of Biotechnology Wellcome Trust India Alliance (IA/CRC/19/1/610005) and Department of Biotechnology, Government of India (BT/HRD-NBA-NWB/38/2019-20(6)). LBR has received support from FAPESP (grant 2019/07256-7). $\mathrm{MB}$ has received support from NIH (grant 1R01NS112996 and 1R01NS101362). IRV received funding from thr BBSRC (Ref: BB/S008314/1). AHO has received scholarships (Process 13/10187-0 and 14/10134-7) and support from FAPESP (CEPID/BRAINN - The Brazilian Institute of Neuroscience and Neurotechnology Process: 13/07559-3), and the Brazilian National Council of Scientific Development (CNPq 479000/2012-3; 487361/2013-0; PQ-2). LC has received support from the NIH grants NIH 1R01NS112996-01A, R21NS101712-0), US Department of Defense (grant W81XWH-17-1-0320), VA Healthcare (GRANT13010404), and National MS Society (RG-1803-30492). KPB has received support from the Spaulding Research Institute (Spaulding Research Accelerator Program).

\section{References}

1 Fregni F, El-Hagrassy MM, Pacheco-Barrios K, et al. Evidence-Based Guidelines and Secondary MetaAnalysis for the Use of Transcranial Direct Current Stimulation in Neurological and Psychiatric Disorders. Int J Neuropsychopharmacol 2021; 24: 256-313.

2 Ekhtiari $\mathrm{H}$, Tavakoli $\mathrm{H}$, Addolorato $\mathrm{G}$, et al. Transcranial electrical and magnetic stimulation (tES and TMS) for addiction medicine: A consensus paper on the present state of the science and the road ahead. Neurosci Biobehav Rev 2019; 104: 118-40. 
medRxiv preprint doi: https://doi.org/10.1101/2022.03.03.22271837; this version posted March 5, 2022. The copyright holder for this preprint (which was not certified by peer review) is the author/funder, who has granted medRxiv a license to display the preprint in perpetuity. It is made available under a CC-BY-NC-ND 4.0 International license .

3 Fregni F, El-Hagrassy MM, Pacheco-Barrios K, et al. Evidence-based guidelines and secondary metaanalysis for the use of transcranial direct current stimulation (tDCS) in neurological and psychiatric disorders. Int J Neuropsychopharmacol 2020; published online July 26. DOI:10.1093/ijnp/pyaa051.

4 Fregni F, Nitsche MA, Loo CK, et al. Regulatory Considerations for the Clinical and Research Use of Transcranial Direct Current Stimulation (tDCS): review and recommendations from an expert panel. Clin Res Regul Aff 2015; 32: 22-35.

5 Bikson M, Paneri B, Mourdoukoutas A, et al. Limited output transcranial electrical stimulation (LOTES2017): Engineering principles, regulatory statutes, and industry standards for wellness, over-thecounter, or prescription devices with low risk. Brain Stimul 2018; 11: 134-57.

6 Brunoni AR, Nitsche MA, Bolognini N, et al. Clinical research with transcranial direct current stimulation (tDCS): challenges and future directions. Brain Stimul 2012; 5: 175-95.

7 Bikson M, Brunoni AR, Charvet LE, et al. Rigor and reproducibility in research with transcranial electrical stimulation: An NIMH-sponsored workshop. Brain Stimul 2018; 11: 465-80.

8 Charvet LE, Shaw MT, Bikson M, Woods AJ, Knotkova H. Supervised transcranial direct current stimulation (tDCS) at home: A guide for clinical research and practice. Brain Stimul 2020; 13: 686-93.

9 Woods AJ, Antal A, Bikson M, et al. A technical guide to tDCS, and related non-invasive brain stimulation tools. Clin Neurophysiol 2015; published online Nov 22. DOI:10.1016/j.clinph.2015.11.012.

10 Brunoni AR, Sampaio-Junior B, Moffa $A H$, et al. Noninvasive brain stimulation in psychiatric disorders: A primer. Rev Bras Psiquiatr 2019; 41: 70-81.

11 Inan OT, Tenaerts P, Prindiville SA, et al. Digitizing clinical trials. NPJ Digit Med 2020; 3: 101.

12 Insel TR. Digital phenotyping: a global tool for psychiatry. World Psychiatry. 2018; 17: 276-7.

13 Torous J, Onnela J-P, Keshavan M. New dimensions and new tools to realize the potential of RDoC: digital phenotyping via smartphones and connected devices. Trans/ Psychiatry 2017; 7: e1053.

14 Charvet LE, Kasschau M, Datta A, et al. Remotely-supervised transcranial direct current stimulation (tDCS) for clinical trials: guidelines for technology and protocols. Front Syst Neurosci 2015; 9: 26.

15 Silva-Filho E, Pilloni G, Charvet LE, Fregni F, Brunoni AR, Bikson M. Factors supporting availability of home-based Neuromodulation using remote supervision in middle-income countries; Brazil experience. Brain Stimul 2022; 15: 385-7.

16 Torous J, Bucci S, Bell IH, et al. The growing field of digital psychiatry: current evidence and the future of apps, social media, chatbots, and virtual reality. World Psychiatry 2021; 20: 318-35.

17 Razza L. Digitizing Portable Transcranial Electric Stimulation clinical trials: Scoping Review, Process Mapping, and recommendations from a Delphi Panel. 2021; published online Oct 21.

DOI:10.17605/OSF.IO/K83VP.

18 Hsu C-C, Sandford BA. The Delphi Technique: Making Sense of Consensus. Practical Assessment, Research, and Evaluation 2007; 12 : 10.

19 Ekhtiari H, Zare-Bidoky M, Sangchooli A, et al. A methodological checklist for fMRI drug cue reactivity studies: Development and expert consensus. medRxiv 2020. https://www.medrxiv.org/content/10.1101/2020.10.17.20214304v1.full-text.

20 Ekhtiari H, Ghobadi-Azbari P, Thielscher A, Antal A. A Checklist for Assessing the Methodological 
medRxiv preprint doi: https://doi.org/10.1101/2022.03.03.22271837; this version posted March 5, 2022. The copyright holder for this preprint (which was not certified by peer review) is the author/funder, who has granted medRxiv a license to display the preprint in perpetuity. It is made available under a CC-BY-NC-ND 4.0 International license .

Quality of Concurrent tES-fMRI Studies (ContES Checklist): A Consensus Study and Statement. medRxiv 2020. https://www.medrxiv.org/content/10.1101/2020.12.23.20248579v1.full-text.

21 Levac D, Colquhoun H, O’Brien KK. Scoping studies: advancing the methodology. Implement Sci 2010; 5: 69.

22 Zhang Y, Song H, Chen Y, Zuo L, Xia X, Zhang X. Thinking on Transcranial Direct Current Stimulation (tDCS) in Reading Interventions: Recommendations for Future Research Directions. Front Hum Neurosci 2019; 13: 157.

23 Thibaut A, O'Brien AT, Fregni F. Strategies for replacing non-invasive brain stimulation sessions: recommendations for designing neurostimulation clinical trials. Expert Rev Med Devices 2017; 14: 63349.

24 Sierawska A, Prehn-Kristensen A, Moliadze V, et al. Unmet Needs in Children With Attention Deficit Hyperactivity Disorder-Can Transcranial Direct Current Stimulation Fill the Gap? Promises and Ethical Challenges. Front Psychiatry 2019; 10: 334.

25 Kim D-J, Moussa-Tooks AB, Bolbecker AR, et al. Cerebellar-cortical dysconnectivity in resting-state associated with sensorimotor tasks in schizophrenia. Hum Brain Mapp 2020; 41: 3119-32.

26 Fried PJ, Santarnecchi E, Antal A, et al. Training in the practice of noninvasive brain stimulation: Recommendations from an IFCN committee. Clin Neurophysiol 2021; 132: 819-37.

27 Deer TR, Mekhail N, Provenzano D, et al. The appropriate use of neurostimulation of the spinal cord and peripheral nervous system for the treatment of chronic pain and ischemic diseases: the Neuromodulation Appropriateness Consensus Committee. Neuromodulation 2014; 17: 515-50; discussion 550.

28 Sandars M, Cloutman L, Woollams AM. Taking Sides: An Integrative Review of the Impact of Laterality and Polarity on Efficacy of Therapeutic Transcranial Direct Current Stimulation for Anomia in Chronic Poststroke Aphasia. Neural Plast 2016; 2016: 8428256.

29 Parikh SV, Quilty LC, Ravitz P, et al. Canadian Network for Mood and Anxiety Treatments (CANMAT) 2016 Clinical Guidelines for the Management of Adults with Major Depressive Disorder: Section 2. Psychological Treatments. Can J Psychiatry 2016; 61: 524-39.

30 Legatt AD, Emerson RG, Epstein CM, et al. ACNS Guideline: Transcranial Electrical Stimulation Motor Evoked Potential Monitoring. J Clin Neurophysiol 2016; 33: 42-50.

31 Lefaucheur J-P, Antal A, Ayache SS, et al. Evidence-based guidelines on the therapeutic use of transcranial direct current stimulation (tDCS). Clin Neurophysiol 2017; 128: 56-92.

32 Gillick BT, Gordon AM, Feyma T, et al. Non-Invasive Brain Stimulation in Children With Unilateral Cerebral Palsy: A Protocol and Risk Mitigation Guide. Front Pediatr 2018; 6: 56.

33 Cruccu G, Garcia-Larrea L, Hansson P, et al. EAN guidelines on central neurostimulation therapy in chronic pain conditions. Eur J Neurol 2016; 23: 1489-99.

34 Bikson M, Hanlon CA, Woods AJ, et al. Guidelines for TMS/tES Clinical Services and Research through the COVID-19 Pandemic. DOI:10.31234/osf.io/82bmu.

35 Antal A, Alekseichuk I, Bikson M, et al. Low intensity transcranial electric stimulation: Safety, ethical, legal regulatory and application guidelines. Clin Neurophysiol 2017; 128: 1774-809.

36 Shiozawa P, Cordeiro Q, Cho HJ, Trevizol AP, Brietzke E. A critical review of trials of transcranial direct 
medRxiv preprint doi: https://doi.org/10.1101/2022.03.03.22271837; this version posted March 5, 2022. The copyright holder for this preprint (which was not certified by peer review) is the author/funder, who has granted medRxiv a license to display the preprint in perpetuity. It is made available under a CC-BY-NC-ND 4.0 International license .

current stimulation and trigeminal nerve stimulation for depression: the issue of treatment-emergent mania. Trends Psychiatry Psychother 2017; 39: 48-53.

37 Santos FH, Mosbacher JA, Menghini D, Rubia K, Grabner RH, Cohen Kadosh R. Effects of transcranial stimulation in developmental neurocognitive disorders: A critical appraisal. Prog Brain Res 2021; 264: $1-40$.

38 Sanches C, Stengel C, Godard J, et al. Past, present, and future of non-invasive brain stimulation approaches to treat cognitive impairment in neurodegenerative diseases: Time for a comprehensive critical review. Front Aging Neurosci 2021; 12: 578339.

39 McClintock SM, Kallioniemi E, Martin DM, Kim JU, Weisenbach SL, Abbott CC. A Critical Review and Synthesis of Clinical and Neurocognitive Effects of Noninvasive Neuromodulation Antidepressant Therapies. Focus 2019; 17: 18-29.

40 Maatoug R, Bihan K, Duriez P, et al. Non-invasive and invasive brain stimulation in alcohol use disorders: A critical review of selected human evidence and methodological considerations to guide future research. Compr Psychiatry 2021; 109: 152257.

41 Lucchiari C, Sala PM, Vanutelli ME. Promoting Creativity Through Transcranial Direct Current Stimulation (tDCS). A Critical Review. Front Behav Neurosci 2018; 12 : 167.

42 Godeiro C, França C, Carra RB, et al. Use of non-invasive stimulation in movement disorders: a critical review. Arq Neuropsiquiatr 2021; 79: 630-46.

43 Cappon D, Jahanshahi M, Bisiacchi P. Value and Efficacy of Transcranial Direct Current Stimulation in the Cognitive Rehabilitation: A Critical Review Since 2000. Front Neurosci 2016; 10: 157.

44 Workman CD, Fietsam AC, Rudroff T. Tolerability and Blinding of Transcranial Direct Current Stimulation in People with Parkinson's Disease: A Critical Review. Brain Sci 2020; 10. DOI:10.3390/brainsci10070467.

45 ALHarbi MF, Armijo-Olivo S, Kim ES. Transcranial direct current stimulation (tDCS) to improve naming ability in post-stroke aphasia: A critical review. Behavioural Brain Research. 2017; 332: 7-15.

46 Brunoni AR, Fregni F. Clinical trial design in non-invasive brain stimulation psychiatric research. Int $J$ Methods Psychiatr Res 2011; 20: e19-30.

47 Bikson M, Grossman P, Thomas C, et al. Safety of Transcranial Direct Current Stimulation: Evidence Based Update 2016. Brain Stimul 2016; 9: 641-61.

48 Martelletti $\mathrm{P}$, Jensen $\mathrm{RH}$, Antal $\mathrm{A}$, et al. Neuromodulation of chronic headaches: position statement from the European Headache Federation. J Headache Pain 2013; 14: 86.

49 Grimaldi G, Argyropoulos GP, Boehringer A, et al. Non-invasive Cerebellar Stimulation-a Consensus Paper. Cerebellum 2014; 13: 121-38.

50 Buch ER, Santarnecchi E, Antal A, et al. Effects of tDCS on motor learning and memory formation: A consensus and critical position paper. Clin Neurophysiol 2017; 128: 589-603.

51 Baptista AF, Fernandes AMBL, Sá KN, et al. Latin American and Caribbean consensus on noninvasive central nervous system neuromodulation for chronic pain management (LAC2-NIN-CP). Pain Rep 2019; 4: e692.

52 Aparício LVM, Guarienti F, Razza LB, Carvalho AF, Fregni F, Brunoni AR. A Systematic Review on the Acceptability and Tolerability of Transcranial Direct Current Stimulation Treatment in Neuropsychiatry 
medRxiv preprint doi: https://doi.org/10.1101/2022.03.03.22271837; this version posted March 5, 2022. The copyright holder for this preprint (which was not certified by peer review) is the author/funder, who has granted medRxiv a license to display the preprint in perpetuity. It is made available under a CC-BY-NC-ND 4.0 International license .

Trials. Brain Stimul 2016; 9: 671-81.

53 Moffa $\mathrm{AH}$, Brunoni AR, Fregni $\mathrm{F}$, et al. Safety and acceptability of transcranial direct current stimulation for the acute treatment of major depressive episodes: Analysis of individual patient data. J Affect Disord 2017; 221: 1-5.

54 Polhemus AM, Novák J, Ferrao J, et al. Human-Centered Design Strategies for Device Selection in mHealth Programs: Development of a Novel Framework and Case Study. JMIR Mhealth Uhealth 2020; 8: e16043.

55 Darrow JJ, Avorn J, Kesselheim AS. FDA Regulation and Approval of Medical Devices: 1976-2020. JAMA 2021; 326: 420-32.

56 Antich-Isern P, Caro-Barri J, Aparicio-Blanco J. The combination of medical devices and medicinal products revisited from the new European legal framework. Int J Pharm 2021; : 120992.

57 Onodera R, Sengoku S. Innovation process of mHealth: An overview of FDA-approved mobile medical applications. Int J Med Inform 2018; 118: 65-71.

58 Aljedaani B, Babar MA. Challenges With Developing Secure Mobile Health Applications: Systematic Review. JMIR Mhealth Uhealth 2021; 9: e15654.

59 Milev RV, Giacobbe P, Kennedy SH, et al. Canadian Network for Mood and Anxiety Treatments (CANMAT) 2016 Clinical Guidelines for the Management of Adults with Major Depressive Disorder: Section 4. Neurostimulation Treatments. Can J Psychiatry 2016; 61: 561-75.

60 Fonteneau C, Mondino M, Arns M, et al. Sham tDCS: A hidden source of variability? Reflections for further blinded, controlled trials. Brain Stimul 2019; 12: 668-73.

61 Turner C, Jackson C, Learmonth G. Is the 'end-of-study guess' a valid measure of sham blinding during transcranial direct current stimulation? Eur J Neurosci 2021; 53: 1592-604.

62 Eilam-Stock T, George A, Lustberg M, Wolintz R, Krupp LB, Charvet LE. Telehealth transcranial direct current stimulation for recovery from Post-Acute Sequelae of SARS-CoV-2 (PASC). Brain Stimul 2021; 14: 1520-2.

63 Alonzo A, Fong J, Ball N, Martin D, Chand N, Loo C. Pilot trial of home-administered transcranial direct current stimulation for the treatment of depression. J Affect Disord 2019; 252: 475-83. 
medRxiv preprint doi: https://doi.org/10.1101/2022.03.03.22271837; this version posted March 5, 2022. The copyright holder for this preprint (which was not certified by peer review) is the author/funder, who has granted medRxiv a license to display the preprint in perpetuity.

It is made available under a CC-BY-NC-ND 4.0 International license .

Table 1. Comparison of SIPOC processes of trials in which digital features are present and absent.

\begin{tabular}{|c|c|c|c|c|}
\hline Digital features & Suppliers & Inputs & Outputs & Clients \\
\hline \multicolumn{5}{|c|}{ Process: Recruitment } \\
\hline Absent & $\begin{array}{l}\text { Traditional } \\
\text { Media }\end{array}$ & Telephone call or email & \begin{tabular}{|c|} 
Pool of volunteers \\
constrained due to \\
geographical barriers
\end{tabular} & $\begin{array}{l}\text { Pre-screening / } \\
\text { screening onsite } \\
\text { teams }\end{array}$ \\
\hline Present & \begin{tabular}{|} 
Targeted Social \\
Media and \\
Google Ads, \\
public \\
segmentation
\end{tabular} & Electronic forms, ChatBots & $\begin{array}{l}\text { Larger pool of } \\
\text { volunteers }\end{array}$ & $\begin{array}{l}\text { Online pre-screening } \\
\text { / screening teams }\end{array}$ \\
\hline \multicolumn{5}{|c|}{ Process: Pre-screening } \\
\hline Absent & Volunteers & $\begin{array}{l}\text { Onsite checklist of eligibility } \\
\text { criteria }\end{array}$ & Potential Participants & $\begin{array}{l}\text { Onsite screening } \\
\text { team }\end{array}$ \\
\hline Present & Volunteers & $\begin{array}{l}\text { Online assessments, Al } \\
\text { techniques can increase } \\
\text { likelihood of inclusion }\end{array}$ & Potential Participants & $\begin{array}{c}\text { Online screening } \\
\text { team }\end{array}$ \\
\hline \multicolumn{5}{|c|}{ Process: Screening } \\
\hline Absent & $\begin{array}{l}\text { Potential } \\
\text { participants }\end{array}$ & $\begin{array}{l}\text { Onsite clinical interview; } \\
\text { written consent }\end{array}$ & Participants & Onsite clinical team \\
\hline Present & $\begin{array}{l}\text { Potential } \\
\text { participants }\end{array}$ & $\begin{array}{c}\text { Clinical interviews aided by } \\
\text { digital assessments; digital } \\
\text { consent }\end{array}$ & Participants & Online clinical team \\
\hline \multicolumn{5}{|c|}{ Process: Participation in the trial } \\
\hline Absent & Participants & $\begin{array}{l}\text { Staff delivers tES sessions } \\
\text { and assessments }\end{array}$ & $\begin{array}{l}\text { Completers and } \\
\text { patients who } \\
\text { dropped out }\end{array}$ & $\begin{array}{l}\text { Trial complete; } \\
\text { possibly follow-up } \\
\text { studies }\end{array}$ \\
\hline Present & Participants & $\begin{array}{l}\text { tES devices shipped to } \\
\text { participants; online videos } \\
\text { and telesupport to guide self- } \\
\text { applied tES; digital } \\
\text { assessments via online } \\
\text { interviews and mHealth } \\
\text { technologies }\end{array}$ & $\begin{array}{l}\text { Completers and } \\
\text { patients who } \\
\text { dropped out }\end{array}$ & $\begin{array}{l}\text { Trial complete; } \\
\text { possibly follow-up } \\
\text { studies }\end{array}$ \\
\hline
\end{tabular}

The table illustrates how processes of clinical trials can be leveraged using digital approaches. In a) recruitment, volunteers, unconstrained by geographical barriers, can fill out electronic forms and be automatically excluded according to eligibility criteria; b) 
medRxiv preprint doi: https://doi.org/10.1101/2022.03.03.22271837; this version posted March 5, 2022. The copyright holder for this preprint (which was not certified by peer review) is the author/funder, who has granted medRxiv a license to display the preprint in perpetuity.

It is made available under a CC-BY-NC-ND 4.0 International license .

pre-screening, potential participants can be scheduled and contacted automatically for online screening (a step that can be enriched by using machine learning algorithms); c) screening, enrolled participants can provide digital consent, have transcranial electric stimulation (tES) devices shipped to their homes, and being instructed how to use them via videos and/or augmented reality techniques; and d) participation in the trial, interaction with the staff can be mediated by psychiatric chatbots for filtering between simple questions, reporting of adverse events and need of medical care. 
medRxiv preprint doi: https://doi.org/10.1101/2022.03.03.22271837; this version posted March 5, 2022. The copyright holder for this preprint (which was not certified by peer review) is the author/funder, who has granted medRxiv a license to display the preprint in perpetuity.

It is made available under a CC-BY-NC-ND 4.0 International license.

Figure 1: Study workflow. First, the steering committee (SC) was formed, including prominent researchers in the field. Then, supplemented by the results of a systematic review conducted on tES trials, the SC developed the questionnaire, which was sent to all participants of the study (SC and expert panel (EP)) to answer it. Simultaneously, companies producing tES devices were contacted, based on the companies known by the SC and EP, to provide details about the available devices. Finally, the SC analyzed the data received from the questionnaire and all participants took part in reporting the results.

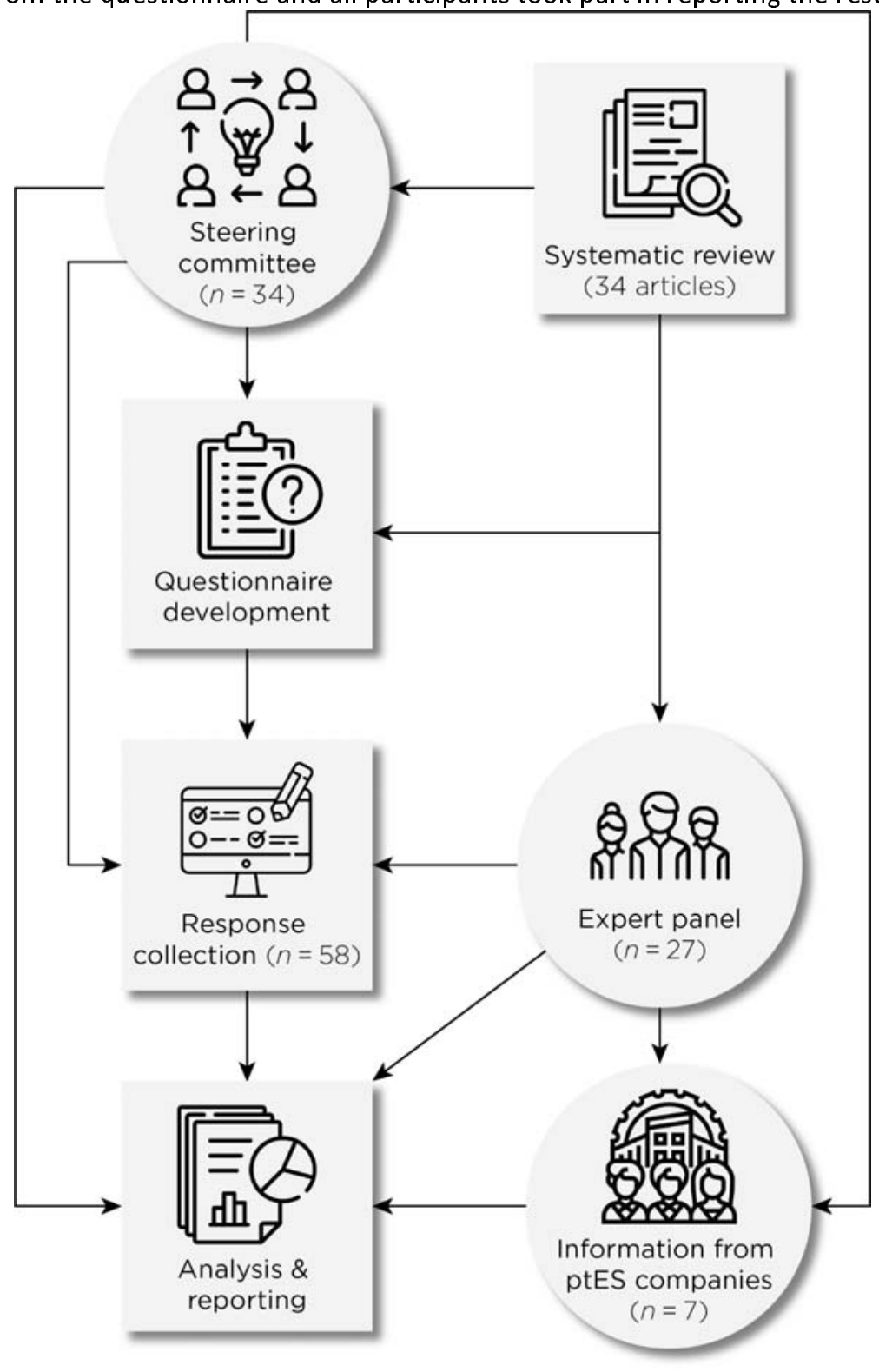


medRxiv preprint doi: https://doi.org/10.1101/2022.03.03.22271837; this version posted March 5, 2022. The copyright holder for this preprint (which was not certified by peer review) is the author/funder, who has granted medRxiv a license to display the preprint in perpetuity.

It is made available under a CC-BY-NC-ND 4.0 International license .

Figure 2: Digitalization readiness of tES devices. Based on the feedback of 8 out of 13 major transcranial electric current stimulation (tES) companies, we evaluated the readiness of these systems for digital trials, considering their connectivity (capability of communicating with other devices and the Web, due to presence of Bluetooth, Wi-Fi, $3 G / 4 G / 5 G$, and communication with third-party apps), methodological aspects (randomization, sham, blinding, built-in data collection, optional data collection, and optional research dashboard), parameter space flexibility (current intensity, session duration, number of sessions, electrode positioning), ecological footprint (rechargeability and replaceability of batteries, recyclability and reusability of sponges, and recyclability of devices), front-end interface (smartphone app, touch screen, device itself, no interaction), and data security (compliance to laws such as GDPR, mention of encryption and anonymization procedures, and option for not collecting sensitive data). The questionnaires and rating systems are described in the Sup.Material-Appendix 5.

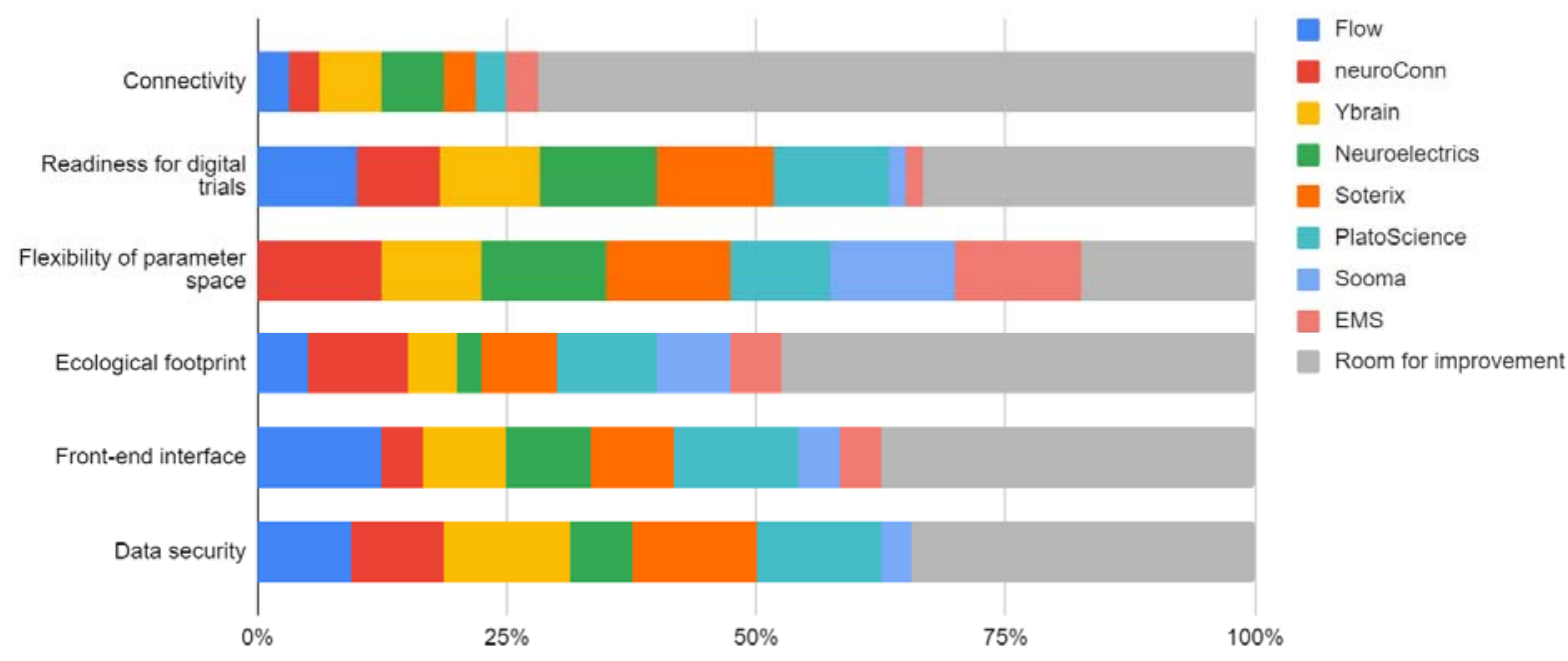


medRxiv preprint doi: https://doi.org/10.1101/2022.03.03.22271837; this version posted March 5, 2022. The copyright holder for this preprint (which was not certified by peer review) is the author/funder, who has granted medRxiv a license to display the preprint in perpetuity.

It is made available under a CC-BY-NC-ND 4.0 International license .

Figure 3: SWOT (Strengths, Weaknesses, Opportunities and Threats) assessment for digital tES trials. This figure depicts the ratings of 55 participants (24 from the steering committee and 31 from the expert panel) for the ptES clinical trials strengths and opportunities (A) and threats and weaknesses (B). Each item was rated from strongly disagree to strongly agree. In ratings for the potential strengths and opportunities of tES clinical trials (A), all of the items have reached the 50\% threshold of agreement (rated as either agree or strongly agree by more than $50 \%$ of the respondents). These items have also reached a more stringent threshold of $60 \%$. However, in ratings for the potential threats and weaknesses of ptES clinical trials (B), two of the items (2.4. Skin burns as a relevant side effect, and 2.6. Higher rates of serious adverse events) did not reach the $50 \%$ threshold. Items are represented by their summary in the figure. Full text of the items is provided in Supplementary Tables 1 and 2. tDCS=transcranial direct current stimulation. ptES=portable transcranial electrical stimulation. DIY=do-ityourself..

A

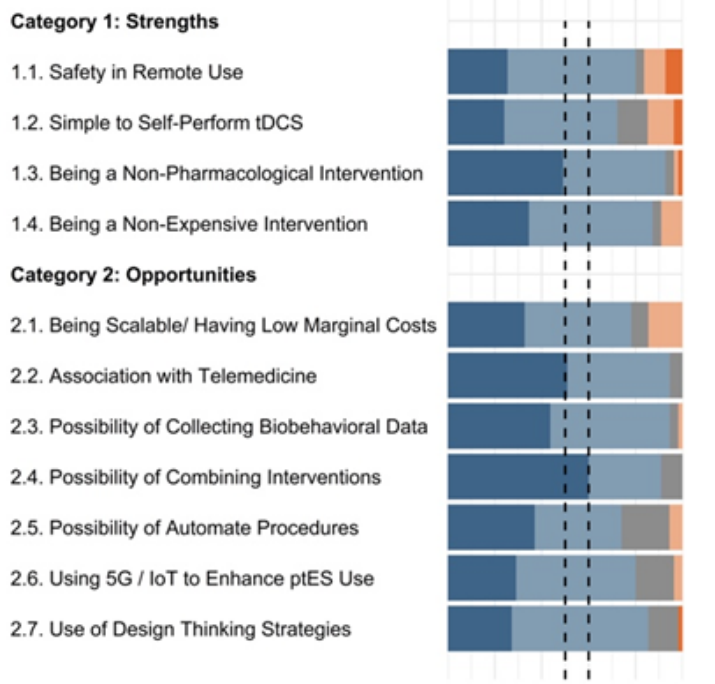

$0 \% 20 \% 40 \% 60 \% 80 \% 100 \%$
B

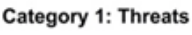

1.1. Potential Cyber-Violations (Hacking)

1.2. Difficulties in Keeping Sensitive Data Safe (Confidentiality)

1.3. Use by Lay People (DIY / Recreational use)

1.4. Unclear Regulatory Status

Category 2: Weaknesses

2.1. Difficulties with Remote Supervision

2.2. Bioethical Issues

2.3. Difficulties with Proper Electrode Positioning

2.4. Skin Burns as a Relevant Side Effect

2.5. Low Clinical Evidence of Efficacy

2.6. Higher Rates of Serious Adverse Events

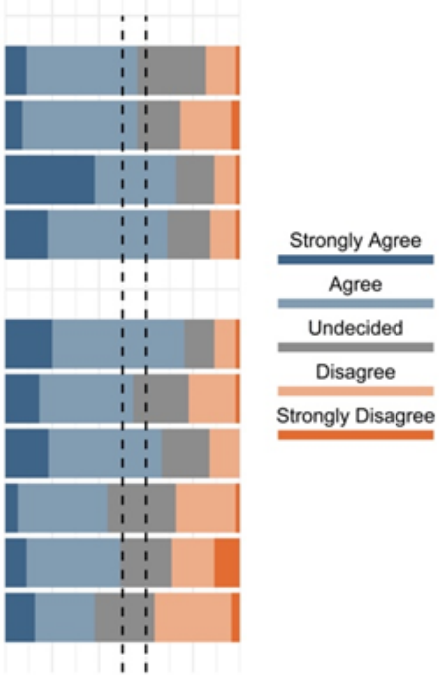

$0 \% 20 \% 40 \% 60 \% 80 \% 100 \%$ 
medRxiv preprint doi: https://doi.org/10.1101/2022.03.03.22271837; this version posted March 5, 2022. The copyright holder for this preprint (which was not certified by peer review) is the author/funder, who has granted medRxiv a license to display the preprint in perpetuity.

It is made available under a CC-BY-NC-ND 4.0 International license .

Figure 4: Ratings for advantages and challenges of conducting tES digital trials. This figure depicts the ratings of 55 raters (24 from the steering committee and 31 from the expert panel) for methodological aspects of tES. Each item was rated from strongly disagree to strongly agree. In ratings for the advantages of transcranial electric stimulation (tES) digital trials from a methodological perspective, only one item (1.8. Greater internal validity) did not reach the agreement threshold of 50\% (rated as either agree or strongly agree by more than $50 \%$ of the respondents). All of the other items in this category also reached a more stringent threshold of $60 \%$. However, in ratings for challenges of tES digital trials from a methodological perspective, 9 items (2.3. Increased risk for suicidality, 2.4. Increased risk for manic switch, 2.5. Increased risk for cognitive effects, 2.6. Increased risk for SAEs, 2.7. ptES will substitute on-site, 2.8. More dropouts, 2.9. More selection biases, 2.10. More randomization biases, and 2.13. More assessment biases) did not reach the $50 \%$ threshold of agreement. With a more stringent threshold of $60 \%$, two additional items (2.11. More blinding biases and 2.12. More sham biases) dropped out from the agreement. Items are represented by their summary in the figure. Full texts of the items are provided in Supplementary Table 3. ptES=portable transcranial electrical stimulation. $\mathrm{SAE}=$ serious adverse event.

\section{Category 1: Advantages}

1.1. Can Use Different Study Designs

1.2. Can Perform Adaptive Trials

1.3. ptES Are Already Well Developed

1.4. Longer Follow-up

1.5. Can Recruit more Participants

1.6. Faster than On-Site

1.7. Greater External Validity

1.8. Greater Internal Validity

1.9. Can Collect more Data

1.10. Can Be Combined with Other Therapies

1.11. Is Scalable

Category 2: Challenges

2.1. Should Be Done Only after On-Site Studies

2.2. Need to Develop New Assessment Methods

2.3. Increased Risk for Suicidality

2.4. Increased Risk for Manic Switch

2.5. Increased Risk for Cognitive Effects

2.6. Increased Risk for SAEs

2.7. ptES Will Substitute On-Site

2.8. More Dropouts

2.9. More Selection Biases

2.10. More Randomization Biases

2.11. More Blinding Biases

2.12. More Sham Biases

2.13. More Assessment Biases

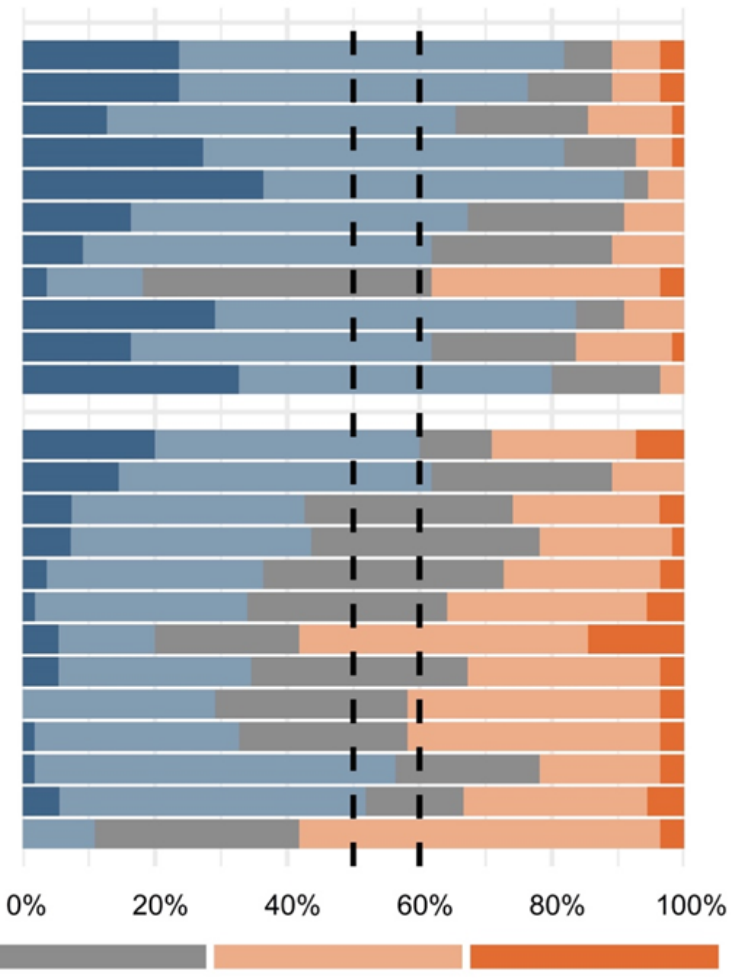

Undecided

Disagree

Strongly Disagree

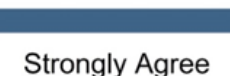

Agree 
medRxiv preprint doi: https://doi.org/10.1101/2022.03.03.22271837; this version posted March 5, 2022. The copyright holder for this preprint (which was not certified by peer review) is the author/funder, who has granted medRxiv a license to display the preprint in perpetuity.

It is made available under a CC-BY-NC-ND 4.0 International license .

Figure 5: Ratings of the tES clinical trials team features and general recommendations on digitizing tES trials. This figure depicts the ratings of 55 participants (24 from the steering committee and 31 from the expert panel) for the ptES clinical trials team features (A) and general recommendations for digitizing ptES clinical trials (B). Each item was rated from strongly disagree to strongly agree. In ratings for the ptES clinical trials team features $(\mathrm{A})$, all of the items have reached the $50 \%$ threshold of agreement (rated as either agree or strongly agree by more than $50 \%$ of the respondents). These items have also reached a more stringent threshold of $60 \%$. Similarly, in ratings for the general recommendations for digitizing ptES clinical trials (B), all of the items have reached the $50 \%$ threshold of agreement. However, with a more stringent threshold of $60 \%$, one item (8. Develop methods to assess AEs) dropped out from the agreement. Items are represented by their summary in the figure. Full text of the items is provided in Supplementary Tables 4 and 5. ptES=portable transcranial electrical stimulation. $\mathrm{AE}=$ adverse event. $\mathrm{SAE}=$ serious adverse event.

A

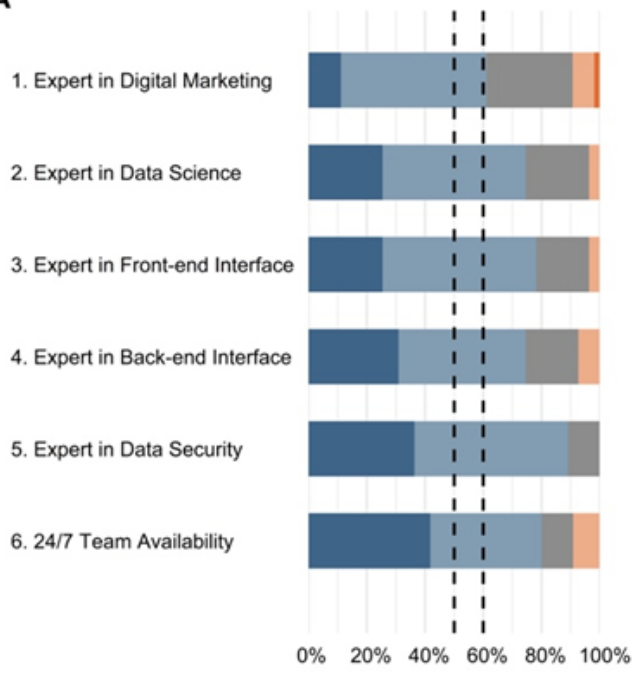

B

1. Develop Better Methods for Randomization and Allocation

2. Develop Better Methods for Sham Stimulation

3. Develop Methods to Decrease Attrition

4. Enhance External Validity

5. Combine ptES with Concomitant Interventions

6. Collect Ecological Data

7. Develop Safe Methods to Store Data

8. Develop Methods to Assess AEs

9. Develop Methods to Assess SAEs

10. Develop Methods to Assess Unexpected AEs

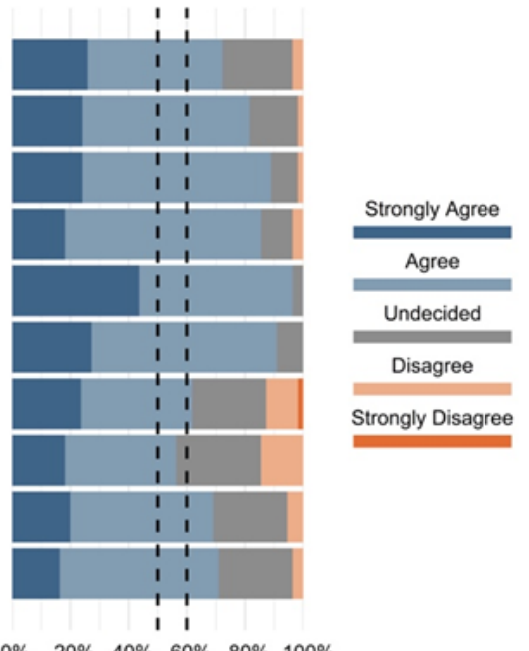

$\begin{array}{llllll}0 \% & 20 \% & 40 \% & 60 \% & 80 \% & 100 \%\end{array}$ 
medRxiv preprint doi: https://doi.org/10.1101/2022.03.03.22271837; this version posted March 5, 2022. The copyright holder for this preprint (which was not certified by peer review) is the author/funder, who has granted medRxiv a license to display the preprint in perpetuity.

It is made available under a CC-BY-NC-ND 4.0 International license .

Figure 6: A conceptual framework for digitizing neuromodulation. As depicted on the left side of the figure, transcranial electric stimulation devices had been relatively simple, essentially using batteries connected to electrodes to deliver constant currents, and contain few (micro) electronic components. Although portable and safe, they had not been specifically designed for use outside hospital or academic center settings. New and future generations of tES will be mobile Health tES systems using digital technologies for improving health outcomes. They are and will be smaller and lighter than previous generations, possessing wireless connectivity. Such devices are already used at home and are self-delivered, usually with some degree of remote supervision. Their use will be supported by proprietary or third-party apps and wearables. Resulting together with the aforementioned concept as digitizing neuromodulation, the right side of the figure shows digital trials as clinical trials that use digital features to enhance recruitment, assessment, and data analysis and could unleash the full potential of tES regarding scalability and equity of access. There are many similarities between the assumptions of digital trials and the capabilities of $\mathrm{mtES}$, which are discussed in this work. EMA=Ecological momentary assessment. mtES=mobile transcranial electrical stimulation.

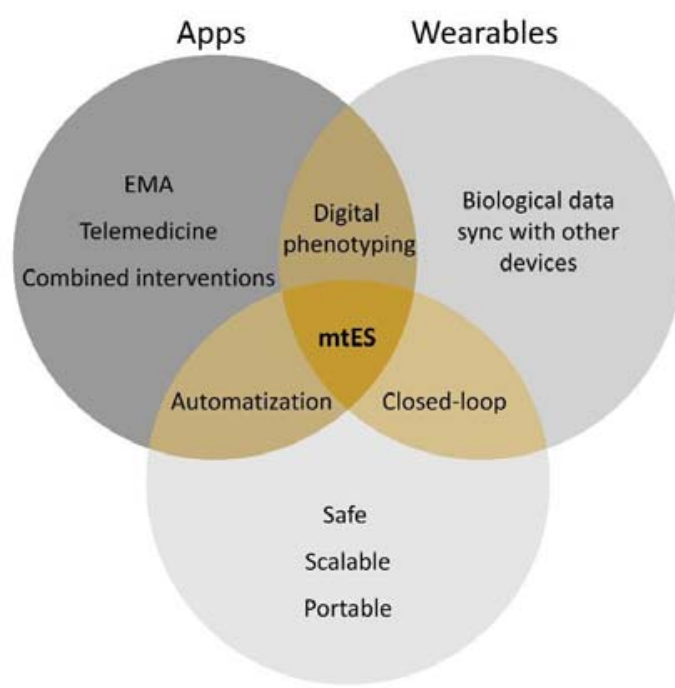

tES Technology

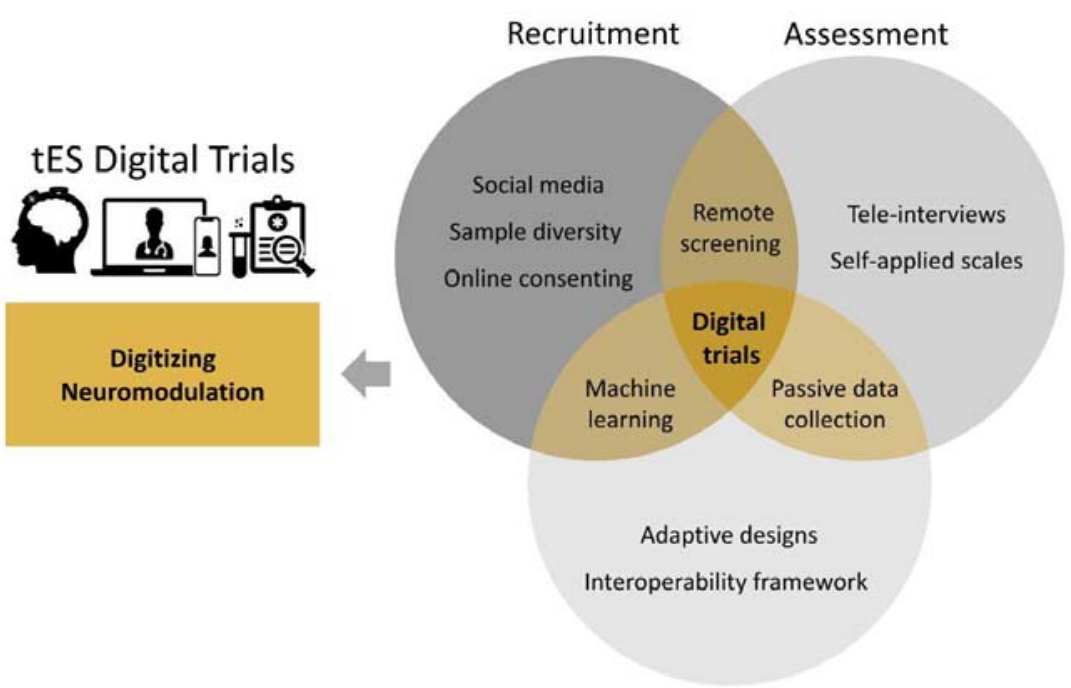

Analytics 